\title{
Un devenir excéntrico. El nonsense en las invitadas, de Silvina Ocampo*
}

\author{
Natalia Biancotto**
}

\begin{abstract}
Resumen
Este trabajo propone leer las formas del nonsense en Las invitadas (1961), de Silvina Ocampo, siguiendo la hipótesis de que estos relatos se organizan según las mismas preocupaciones que alientan la producción inicial y tardía de la autora. Se discute el consenso crítico que define a este momento de su narrativa como una etapa de madurez, determinada por relatos acabados y una lógica compositiva alejada del efecto de fugacidad, tontería y dispersión del sentido de sus primeros y últimos libros. Para ello, se analiza estos cuentos como retratos del momento en que una vida se torsiona en un devenir excéntrico. El resultado expone el modo en que Las invitadas se ubica a mitad de camino entre la "precariedad" de un relato que se acaba en el rasgo idiota del personaje y el "despropósito" de la ficción como registro de la idiotez. Estos cuentos manifiestan una preocupación insistente por las formas de la rareza, ambigüedad e inconclusividad propias del nonsense.
\end{abstract}

Palabras clave: Las invitadas, Silvina Ocampo, excentricidad, devenir, nonsense.

\section{An eccentric becoming. The nonsense in las invitadas, by silvina ocampo}

\begin{abstract}
This work proposes to read Las invitadas (1961), by Silvina Ocampo, according to the hypothesis that these stories are organized by the same concerns that encourage the author's initial and late production. It is proposed to discuss the critical consensus that defines this moment of his narrative as a stage of maturity, determined by finished stories and by a compositional logic away from the effect of transience, foolishness and dispersion of their first and last books. The stories are read as portraits of the moment in which a life twists into an eccentric becoming. The result exposes the way in which Las invitadas is located halfway between the precariousness of a story that ends in the character's idiotic trait is made and the nonsense of a fiction as a record of idiocy. These stories show an insistent concern about the nonsensical forms of rarity, ambiguity and inconclusivity.
\end{abstract}

Key words: Las invitadas, Silvina Ocampo, eccentricity, becoming, nonsense.

Recibido: 12/12/2017

Aceptado: 23/11/2019

Este trabajo forma parte de la investigación doctoral "El nonsense en la narrativa de Silvina Ocampo", realizada en el marco de las Becas Internas de Posgrado (Tipo I y Tipo II) otorgadas por el Consejo Nacional de Investigaciones Científicas y Técnicas (CONICET).

* Argentina. Doctora en Humanidades y Artes con mención en Literatura, de la Universidad Nacional de Rosario. Becaria postdoctoral del Instituto de Estudios Críticos en Humanidades (IECH, Universidad Nacional de Rosario, CONICET) Rosario, Argentina. biancotto@iech-conicet.gob.ar 


\section{Introducción}

Si se ensaya una lectura de conjunto de la narrativa de Silvina Ocampo, puede observarse con cierta claridad un movimiento por el cual los últimos relatos -compilados en los volúmenes $Y$ así sucesivamente (1987) y Cornelia frente al espejo (1988)- se acercan a los primeros -los de su primer libro, Viaje olvidado (1937)- por una serie de rasgos en común, como la forma breve y anómala de sus construcciones, sus tramas fragmentarias e inconclusas, o su atmósfera de rareza y absurdidad. Las lecturas críticas de la obra de Ocampo coinciden en este punto, como también en señalar que las colecciones de relatos que la autora publicó entre los primeros y los últimos libros definirían su obra de madurez (cfr. Tomassini), que comprendería La furia y otros cuentos (1959), Las invitadas (1961) y Los días de la noche (1970). Esta etapa de su producción estaría caracterizada por la forma acabada de los cuentos, de estructura más tradicional y "cerrada", es decir, por una lógica compositiva alejada de los efectos de fugacidad, tontería y dispersión del sentido característicos del primero y los dos últimos volúmenes. En divergencia con este criterio, la idea que alienta este trabajo propone que este momento de su narrativa se encuentra en directa vinculación con su obra temprana y tardía, con la rareza, ambigüedad e inconclusividad que caracteriza a esos cuentos, en tanto responden a una preocupación insistente por las formas del nonsense. A partir de esta idea de nonsense, fundamentada principalmente en la conceptualización de Gilles Delleuze (1969), propongo que la búsqueda narrativa de Ocampo manifiesta un interés decisivo tanto por los tópicos y procedimientos del nonsense carrolliano -según algunos críticos ya han señalado, sin ahondar en el análisis (cf. Ulla, Sánchez, Mancini y Panesi)- como por aquellos propios de los limericks de Edward Lear (cfr. Biancotto, 2016).

Me ocuparé aquí de presentar una lectura de Las invitadas, a partir de la hipótesis general de que estos cuentos ponen de manifiesto una exploración sostenida con las formas del nonsense en la narrativa ocampiana, que se intensifica en las últimas compilaciones. Específicamente, intentaré describir el modo en que estos cuentos presentan el retrato de una vida trastornada en su devenir excéntrico, a partir de una lógica del relato que transforma los atributos de la precariedad y el despropósito en formas de la ficción. 


\section{La excentricidad nonsensical}

Los cuentos de Las invitadas a menudo capturan el momento en que se revela la excentricidad del protagonista; ese gesto, ese rasgo singular que, por una suerte de nominalismo a lo Humpty Dumpty, ya está anunciado en el nombre propio ${ }^{1}$. Considerados como el retrato de una excentricidad -antes que de ningún otro aspecto del personaje (su historia, su ámbito, su psicología, etc.)-, como la instantánea tomada en el preciso momento en que una vida se torsiona en un devenir excéntrico, anticipan la forma de los llamados "cuentos limerick" de Y así sucesivamente (cfr. Biancotto, 2016).

Si Viaje olvidado presenta una galería de losers inocentes; La furia, una de freaks o excéntricos de feria; Las invitadas inaugura la serie de los lejanos, idiotas o maniáticos, que definirá los caracteres de los últimos cuentos de Ocampo, bajo el signo del nonsense leariano, como si cada relato fuera el retrato no del personaje, sino de su idiotez-excentricidad. A mitad de camino entre la "precariedad" de un relato que termina en cuanto concluye la presentación del rasgo idiota del personaje y el “despropósito" de la ficción como registro de una idiotez.

A menudo los protagonistas son nombrados por los "otros" que los rodean -"they" es el colectivo cruel que en los limericks de Lear descarga toda su violencia sobre el protagonista- con fórmulas del tipo "ahí va el idiota" (cfr. "Isis", “La revelación”). El despropósito, la inutilidad y la torpeza son los rasgos recurrentes de estos seres marginales, siempre descolocados. "El nonsense -afirma Susan Stewart- se vuelve apropiado sólo para el discurso cotidiano de lo socialmente inútil, para aquellos en las periferias de la vida cotidiana: los infantes, los niños, los locos y los viejos, los tontos y bromistas crónicos" (5).

Edimia Urbino, quien más tarde se convertirá en "Amelia Cicuta” en el cuento homónimo, "era como una especie de fotografía fuera de foco de su hermana" (el destacado es propio; 32 ) 2 . Se la pinta como una trastornada que, lisa y llanamente, no sirve para nada: "Edimia Urbino servía sólo para rematar las costuras y acomodar en las perchas los

En una dirección similar, aunque refiriéndose a los cuentos de Y así sucesivamente y Cornelia frente al espejo, Carlos Dámaso Martínez dice que los nombres propios “parecerían ser el punto de partida de sus invenciones fantásticas, de la creación de un universo ficcional que se constituye -como en la poesía- desde y por el poder sugeridor de las propias palabras" (s/p).

De aquí en adelante, y hasta que se indique lo contrario, todas las citas corresponden a la edición de Las invitadas de Ediciones Orión, 1979. Solo consigno, por lo tanto, el número de página entre paréntesis. 
vestidos, para abrir la puerta a las clientas y para pasar la escoba por el piso, para juntar las agujas o los alfileres caídos, cuando las clientas se habían retirado" (32). Con tanto laconismo como contundencia, el narrador señala: "Le interesaban los gatos" (33). Cada vez que en un cuento de Silvina Ocampo se declara un interés, ese interés se come al personaje, le ocupa la vida entera, esto es, el espacio todo del relato. Que a Edimia le interesen los gatos quiere decir, en esta lógica del relato, que no le interesa ninguna otra cosa, que vive solo para los gatos. "En Buenos Aires hay muchas personas que llevan a Palermo, al Botánico, al Parque Lezama, comida para gatos; pero ella, Edimia, llevaba comida a todos los gatos de la ciudad" (el destacado es propio; 33). La hipérbole es definitiva para subrayar la excentricidad del personaje y el despropósito de la anécdota. No es cualquier amante de los gatos: ese "todos" la vuelve única. Es que en el campo del nonsense, o mejor, en la zona de la narrativa ocampiana que el nonsense ilumina, todo ocurre "al pie de la letra" (Pizarnik, 1994). Que le interesan los gatos, que alimenta a todos los de la ciudad no son "formas de decir", sino justamente el modo en que el relato dice intensamente todo lo que tiene para decir.

Los relatos del nonsense se atienen al universo del enunciado, con esa "sensitiva afinación al sentido que es propia del sinsentido" (Aira 62). Por la ley de necesidad de la narración, la causalidad, se sostiene hasta la insensatez en el despropósito de sus enunciados. Así es como los relatos de Ocampo hablan, necesariamente, la lengua de la hipérbole. Eso que Sylvia Molloy llamó "la exageración como lenguaje”, visto desde la perspectiva del nonsense, se manifiesta como la única vía para que el relato garantice el juego entre despropósito y necesidad absoluta.

El sentido tonto, insensato, de esa expresión, "le interesaban los gatos", sostiene el relato entero hasta hacerlo estallar con literaridad extrema. Porque, si no nos quedó claro desde la primera página, el sintagma "los gatos" ocupa y clausura el lugar transitivo del interés, por lo que no queda sitio alguno para ninguna otra cosa. La dedicación exclusiva a los gatos y nada más que a los gatos toma, evidentemente, "un tinte ominoso de manía”, como encuentra César Aira en muchos limericks de Lear (62), en su riguroso ensayo sobre el autor. A esa literalidad disparatada, que define la lógica del relato, se refería Pizarnik al afirmar que: “[e]n los cuentos de Silvina Ocampo, el humor es obligado a nacer, casi siempre, al pie de la letra o, lo que es igual, del simulacro de la asímbolia o, lo que es igual, basta olvidar que el mundo está hecho de símbolos, para que 
el mundo se vuelva una representación del Gran Hospicio del Mundo" (420).

Las posibilidades narrativas que ofrece la forma cuento, a diferencia de la muchísimo más acotada del limerick, da lugar a la aparición de un segundo maniático en la historia. La locura gatuna de Edimia/Amelia entra en colisión con la manía alimenticia de su natural antagonista, quien tiene el extraño hábito de comer gatos y se hace llamar Torcuato Angora. También como en los limericks, en los que son frecuentes los casos de "alimentación exclusiva" (Aira 74), aparece este segundo personaje que declara que el hábito de comer gatos "[n]o es por economía, es por costumbre" (36). No solo su apellido es el de una raza felina, sino que "Torcuato" rima con "gato": si, como suele suceder en los cuentos de Ocampo, el nombre declara la excentricidad de carácter, también el hábito (en este caso alimenticio) se come al personaje, como en una expansión narrativa del "dime qué comes y te diré quién eres".

En esa delirante cadena alimenticia en que Edimia/Amelia da de comer a todos los gatos de la ciudad (con los mejores y más caros cortes de carne, por otra parte), y estos, a su vez, son alimento de Torcuato Angora, quien los engorda para comérselos, se cifra toda la secuencia argumental del cuento. Como si la trama, pegada a los avatares del enunciado, consistiera precisamente en el desplazamiento de objetos del verbo "comer". En esta lógica, se vuelve necesario que el ajusticiamiento final involucre los términos de la comida: la mujer da de comer al Gato Maestro carne envenenada, para que luego el hombre devore ese banquete disfrazado de ofrenda sincera, pero destinado a ser el último.

El excesivo (único y total) interés de Edimia por los gatos entabla un diálogo con el del personaje del cuento "Isis" y su fascinación por el animal del zoológico en el que, se sobreentiende, se transforma al final del cuento, y también con el de la mujer de "El automóvil", de $Y$ así sucesivamente, que termina convertida en máquina, producto de su obsesión por los autos. Esta manía, sumada a las repetidas referencias a sus maullidos ("emitió un maullido perfecto" [31]; "Edimia maulló de nuevo" [32]), hacen pensar que la mujer se convertirá en gato hacia el final del relato. Sería natural, en esta secuencia, que algo así ocurriera. La transformación de Edimia en Amelia, sin embargo, le da una vuelta más a la serie: la mujer asume, en vez de un cuerpo gatuno, el lugar común de la traición atribuido por el lenguaje popular a estos animales. Si las metamorfosis en Ocampo siempre involucran 
la literalización de metáforas o expresiones cristalizadas, en este caso se trata de versionar lugares comunes y frases hechas sobre los gatos. Variaciones de una "traición con gato", además del guiño al clásico mote del "gato traicionero", Amelia intenta venderle a Torcuato "gato por liebre", para que, tal vez, al final pueda concluirse que "la curiosidad mató al gato".

Tanto el carácter maníaco del personaje, la condición al mismo tiempo extrema y tonta de la breve anécdota, como el final un tanto inconcluso, un tanto desalentador (puesto que nunca llegamos a saber si el hombre se come o no al gato envenenado), entre otros rasgos en este relato, aluden a la estructura de un limerick. Sin animarme a arriesgar la rima, este se correspondería en líneas generales con el siguiente esquema: "Había una joven de Buenos Aires, que amaba mucho a los gatos; un día quiso envenenar a un hombre, que acostumbraba a comérselos, esa peculiar joven de Buenos Aires". El cuento no dice mucho más que lo que puede resumirse en estas líneas, pero sí añade la mezcla de culpa y goce de la mujer por haberse ganado el nombre de "Amelia Cicuta". El antagonista, que en los limericks se circunscribe a un ambiguo plural ("they"), es aquí el reverso exacto de la excéntrica protagonista, y detenta una locura análoga a la suya. “El sitio al que llega el 'había una vez' del limerick -dice Aira- es instantáneo: contiguo, y a la vez imprevisible y lejano" (50). El destino del cuento de Ocampo tiene algo de ese lugar instantáneo: contiguo, porque el relato es la natural consecución de la primera postulación - "le interesaban los gatos"-, pero, al mismo tiempo, llega hasta lo insospechado. El carácter cada vez más "lejano” que va ganando la protagonista en el curso del relato (de la zoncera inicial a la locura final), tan lejano y extremo que hasta se le vuelve necesario cambiar de nombre, es signo incontestable de la excentricidad que singulariza a los personajes de Ocampo, según la serie que estamos reconstruyendo.

Más que de la doble personalidad del justiciero -aunque resulte tentador pensar en una "superheroína de los gatos" -, de lo que se trata acá es del modo en que Edimia Urbino es reemplazada y absorbida por Amelia Cicuta: "de nada le valdría llamarse Edimia Urbino, haber nacido en una casa con un patio que tenía una estatua de Baco sosteniendo racimos. Como si su vida entera hubiera transcurrido sólo en Almagro, en ese terreno baldío, su nombre valedero era Amelia Cicuta" (37). La fuerza del nombre propio -que no existe en los limericks, salvo para 
los topónimos, de tal modo que el personaje queda intrínsecamente determinado por su lugar de origen- constituye, por lo demás, un rasgo singular y no menor entre los que definen el nonsense en Silvina Ocampo. Sobre la cuestión del nombre, dice Matilde Sánchez:

Se ha señalado que Alicia en el País de las Maravillas cuenta la aventura de perder el nombre propio. Es notorio cuánto deben los relatos de Silvina a las novelas de Lewis Carroll, tanto en sus personajes infantiles y el tratamiento naïf de hechos atroces, como en la desnaturalización de la estructura de los relatos infantiles [...] Contrariamente al escritor inglés, la metamorfosis ocampiana no constituye la pérdida del nombre propio sino su triunfo, en la medida en que la transformación se refiere como un "caso clínico". Así, gran cantidad de sus cuentos llevan por título el nombre del personaje prodigioso, como si éste fuera la cifra o clave del proceso. (152-153)

En realidad, muchos de los cuentos de Ocampo sí son la aventura de perder el nombre propio para ganar el apodo. El apósito que se pega sobre el nombre y lo recubre, el nombre "de fantasía”, es, en definitiva, más real que el verdadero, porque tiene la capacidad de representar el carácter, la singularidad del personaje, como quería Humpty Dumpty. El sinsentido consiste en hacer coincidir palabras y cosas, en hacer corresponder la locura del nombre con la locura del excéntrico que lo porta.

¿En qué mundo alguien se llama Amelia Cicuta o Torcuato Angora? Pues en el de un relato que designa con nombre y apellido su peripecia en miniatura. La aventura que cuenta el cuento no es otra que la de hacerse con ese nombre propio de fábula. Locura y excentricidad coinciden con la aventura del relato. Por eso se trata del despropósito o del sinsentido como lógica de la invención, y no de locura "clínica", como dice Sánchez: "nombres 'anormales' [...] pues habrán de nombrar un síntoma” (153154). Si bien acordamos con su descripción de estos cuentos como un “archivo de «casos excéntricos»" (9), Sánchez entiende el “caso -y por lo tanto el relato-, a la manera de Freud" (153). Creemos, al contrario, que, si se tratara de "enfermos", el despropósito de sus acciones resultaría de lo más natural, al punto de volverse ya no un despropósito, sino simplemente lo esperable, lo propio de un enfermo mental. No se trata, entonces, de patologías o "fallas" de la normalidad, sino de la más categórica excentricidad, que se declara en absoluta distancia, lejanía y exterioridad respecto del sentido común. 
Ese gusto por el personaje disparatado, por un relato que se resuelve en el mero trazo de su excentricidad, tiene una importante tradición inglesa, en la que se revela una sensibilidad humorística signada por "ese sano sentido de lo incongruente" que describe G. K. Chesterton en su ensayo sobre el humorismo (135). Los libros de limericks anónimos que inspiraron a Lear declaran desde el título esa preferencia: La historia de dieciséis ancianas maravillosas. Ilustradas por otros tantos grabados que exhiben sus principales Excentricidades y Diversiones, de 1820, y el que le siguió poco después, Anécdotas y aventuras de quince caballeros, de $1822^{3}$. Aventura, anécdota, excentricidad y diversión son las claves para accionar el "mecanismo automático" del limerick, que permite contar la anécdota de un excéntrico relato ${ }^{4}$. No es este, sin embargo, el caso de la ficción de Ocampo: ni mecanismo automático ni máquina de hacer cuentos, sino, antes bien, una lógica de la invención que sigue de cerca esos movimientos del desatino inglés.

La aventura del relato nace de la breve, incluso insignificante, anécdota por la que un personaje muestra el devenir de su excentricidad. La resolución de esa aventura es necesariamente humorística, siempre que por esto se entienda el modo de asegurar la frustración del sentido, el efecto de descolocación, de malentendido. Así, la estructura de los cuentos y, especialmente, la cuidadosa manera en que finalizan, produce deliberadamente el sinsentido como malentendido. El entendido se esquiva con sutileza, puesto que "el sentido amenaza colarse a la menor distracción: la pendiente del menor esfuerzo, o del hábito, lleva al sentido: el sinsentido es una divergencia" (Aira 15-16). Ahora bien, el reconocimiento de esta divergencia, en el sentido de la inconclusividad dada por las derivas posibles que el final deja abiertas, está a cargo del lector. Lo mismo pasa con el registro de la anomalía del personaje: quienes acompañan al excéntrico no lo perciben como tal. Se plantea, entonces, una situación narrativa de origen teatral, en la que el sinsentido es percibido por un tercero, el lector, que, por lo tanto, guardará siempre

\footnotetext{
Los títulos originales de estos libros editados en forma anónima -cuyo autor, según se conjetura, fue posiblemente R. S. Sharpe- son: The History of Sixteen Wonderful Old Women. Ilustrated by as many engravings: exhibiting their principal Eccentricities and Amusements, y Anecdotes and Adventures of Fifteen Gentlemen. Ambos llevan las ilustraciones del célebre caricaturista Robert Cruikshank.

Esta fórmula automática es la que fascina a Aira, quien conjetura, a propósito: "Es posible que haya habido más libros de este tipo antes de Lear: la idea de un libro que se hace solo, mecánicamente, de a un personaje por página, sobre un catálogo tan inagotable como la humanidad y el mundo y la lengua, es demasiado buena para no atraer a más de un autor anónimo" (14).
} 
la esperanza de no ser el único, de que alguien más "se dé cuenta" y haga algo con el desatino del excéntrico, expectativa tantas veces renovada como invariablemente frustrada.

Propuse antes el esquema que seguiría un limerick basado en este cuento. La última línea repetiría, por regla general, a la primera. Este es el modo en el que la forma del limerick resguarda su desatino y, junto con él, su humor de chiste sin remate: al anular el efecto produce el sinsentido como efecto. En el cuento de Ocampo, el modo de resguardar el sinsentido es anular la reconstrucción de sentido última (igual que ocurre en el caso del chiste al que le falta el final). Finalizada la lectura, en el lugar donde debería aparecer la satisfacción del entendido, irrumpen una tras otra las preguntas: ¿Se habrá comido al gato envenenado? ¿Por qué no aparece, entonces, la noticia correspondiente en el diario, que Edimia/Amelia reconocería, aún si en vez de "Torcuato Angora” figurara su verdadero nombre? ¿Es que se habrá percatado a tiempo, echando por tierra el plan de Amelia? Y, más allá incluso de estas cuestiones estrictamente argumentales, uno termina preguntándose: al fin y al cabo, ¿dónde está la gracia de este relato? ¿Cuál es el chiste? Y si estamos de acuerdo en que algo de esta gracia tiene estricta relación con el humor, ¿realmente nos conformamos pensando que ese humor se reduce a los nombres curiosos de los personajes o a la supuesta crítica paródica de ciertas conductas sociales que algunos lectores señalan en estos relatos (cf. Ulla, Tomassini, Aldarondo)? ${ }^{5}$.

Alejandra Pizarnik señaló temprano que los cuentos de Silvina Ocampo dicen incesantemente algo más, otra cosa, que no dicen. Ese modo de narrar que "da a entender" sin explicitar el "entendido", que está siempre a un paso del malentendido o caminando sobre él como en una cuerda floja, requiere de un lector en permanente estado de sospecha, capaz de sucumbir él mismo al encanto del malentendido, de la excentricidad y el despropósito. Quien lee buscando el entendido se suele equivocar: creer, por ejemplo, que el final del cuento no deja

\footnotetext{
Dice, por ejemplo, Noemí Ulla: “En 'La siesta en el cedro' una niña que observa y enjuicia el comportamiento de los mayores, en sus prohibiciones y en sus banalidades, tiene la actitud crítica y escéptica que define otros cuentos con niños posteriores, como La furia y otros cuentos, Las invitadas y La naranja maravillosa. [...] Pero el acento está puesto, como en 'Las dos casas de Olivos', en la discordia social..." (387-388). Asimismo, Graciela Tomassini señala: “El distanciamiento irónico como estrategia textual lleva implícita una visión crítica de las conductas sociales y los discursos que las sancionan" (67). Por su parte, Hiram Aldarondo se refiere a la denuncia de la banalidad, la frivolidad y la hipocresía, así como a la parodia de actitudes y comportamientos de clase (64-65).
} 
lugar a dudas (Sánchez deduce, concluyente, que “Torcuato Angora, habitual catador de gatos, dará su último bocado a la pieza envenenada que le tiende 'Amelia Cicuta'” [152], cuando el relato no otorga, en rigor, tales certezas). Una constante y una marca de la ficción de Ocampo es esa suspensión del sentido, el estado de latencia en que quedan las situaciones una vez finalizado el relato.

En "Isis" esta lógica se lleva un poco más lejos. Para empezar, y tal como les ocurre a los personajes que rodean a la protagonista, el cuento no cesa de no resolver la pregunta $i$ es o se hace? El final exaspera la incertidumbre y la frustración: no solo jamás se aclara en qué animal se convirtió, si es que se convirtió en alguno -al menos esto quisiéramos saber-, sino que tampoco terminamos de entender 'quién' o 'qué era' Isis.

Enunciados como: "Después de comer y de dormir se colocaba frente a la ventana" (83) deslizan el malentendido respecto del sujeto de estas acciones: antes que de una persona, todo parece indicar que se habla de un animal. No habla, no juega, no se mueve; deja caer los objetos entre sus manos (si es que las tiene), no presta la atención ni la mirada a ninguna cosa; mantiene la radical indiferencia de los animales. "Su inmovilidad era más perfecta que la inmovilidad de las águilas, cuando se admiran en la propia sombra, como en un espejo [...] Más perfecta que la del jaguar, que no cierra los ojos sino para dormir o para devorar" (83). La involuntariedad que, junto con la indiferencia y la inmovilidad, la caracteriza (actúa “a pesar de ella” [83]), contradice o descoloca la afirmación según la cual se dice que "era constante en su propósito" (84). Puesto que de "su propósito" nada se predica, tendemos a pensar que este es la nada misma, es decir, el despropósito. Con el firme propósito de no hacer nada, no se podría sostener ni el tener un propósito, a menos que se tenga el propósito de no tener propósito. La inutilidad de este propósito, la ética del despropósito, la coloca en el lugar de la lejanía, el de los excéntricos.

Pertenece a la sociedad cada vez más indiferenciada entre niños, animales, viejos, idiotas y excéntricos, quienes conforman el repertorio de personajes más característico de los cuentos de Silvina Ocampo. No sabemos qué edad tiene, pero sí que está en edad de leer ("tenía libros" [83]), a pesar de lo cual "la madre la trataba como a una niñita de un año" (84). Descolocada incluso dentro del propio ámbito de la niñez, es más bebé que nena, y más animal que humana, y no tanto porque hacia el final de la narración su mano se cubra de pelos y pezuñas, sino porque 
la narración postula de principio a fin su condición híbrida, excéntrica, lejana e insistentemente indefinida. La duda -'quién' o 'qué' es Isis- se proyecta sobre el personaje desde la rareza del nombre-sobrenombre con el que comienza el relato (¿por qué le dicen Isis? ¿Qué tiene que ver esta niña con la mitología egipcia? Y si no tiene nada que ver, ¿qué sentido tiene que de la natural deformación de "Elisa" en "Lisi" pasen a decirle "Isis"?) hasta la sobreentendida transformación final. Si damos por cierto que se convierte en un animal, ¿de qué animal se trata? Todo el relato es un gran ¿qué?, ¿por qué?, ¿para qué? sin respuesta: un gran despropósito. "Cuando no hay ninguna explicación, todo se vuelve explicación”, dice Aira (59): sobreentendemos, entonces, por la ley de gravedad del sentido, que Isis se transforma en el animal que observaba por la ventana. La "niña”, en tanto tal, se pierde ("La perdí" [85] es la frase final del cuento), en la medida en que su nombre propio queda olvidado en la primera línea del relato para no volver a aparecer, mientras el movimiento de la narración le hace ganar progresivamente una impersonalidad -reflejada, además, en la absoluta impropiedad e insensatez del sobrenombre- que se magnifica violentamente al final. Los pelos y pezuñas son huellas del feroz pliegue del ser con la indefinición del pronombre que lo designa: si los atributos de la animalidad son, en este relato, la indeterminación y la vacilación ("uno de los animales" 83; "un animal que no parecía real" 85), al final a Isis le aparece, en lugar de "su" mano, “una mano" (85), indefinida, a la que ya no puede atribuírsele el resto del cuerpo. Como Isis, la mano es "una", lejos de todo, excéntrica a todo. De hecho, el propio cuerpo -ya impropio- desaparece: queda solo un montón de ropa en el suelo. Junto con Isis, el relato se esfuma, se diluye en incertidumbre. Ese estado de indefinición, de latencia, de suspensión del sentido que afecta al personaje es el que tensiona todo el relato con la pregunta singular del nonsense: el problema del entendido ${ }^{6}$.

Esa lectura descolocada que consiste en no terminar de entender qué se nos quiere contar define el "efecto nonsensical" (Tigges 47) de los cuentos de Silvina Ocampo, cuya extrañeza se acentúa en sus dos últimos

\footnotetext{
6 Patricia Klingenberg entiende, al contrario, que hay un sentido oculto, una "intencionalidad obvia" en este relato de Ocampo: "her humorous/horrific transformation into an animal liberates her from the constraints of consciousness" (43) ["su humorística/horrorífica transformación en animal la libera de las ataduras de la conciencia”]. Este efecto liberador que le atribuye a la metamorfosis se encuentra en directa relación con su lectura del valor subversivo de los dispositivos fantásticos. En este sentido, entiende, por ejemplo, que Isis poseía un "poder oculto" que estaría sugerido por el nombre de la diosa egipcia al que remite.
} 
libros publicados en vida. La tensión entre las expectativas provocadas y su frustración le imprime al relato la forma de su gracia incompleta. Pero en Las invitadas el malentendido en la lectura no responde a una falta de claridad del relato, como puede ocurrir en muchos de los cuentos de $Y$ así sucesivamente y Cornelia frente al espejo, sino más bien a un exceso de claridad, de literalidad, que produce sospechas. "Aquí es 'todo más claro', y a la vez, todo más peligroso”, dice Pizarnik (415). Cuando las interpretaciones privilegian la metáfora por sobre la literalidad, tiene lugar con frecuencia la lectura en clave de subversión. Así, en un cuento en el que aparecen niños que dominan a adultos se lee de inmediato la sublevación del oprimido, el simulacro en pequeño de la lucha de fuerzas. En un caso como el de "Isis", la trasformación sugeriría, según esta línea, la reivindicación de la sabiduría del mundo animal por sobre la barbarie humana (cifrada en los que gritan "ahí está la idiota"). La lectura metafórica tiende de este modo a prestarle servicios a la moral. ¿ $\mathrm{Y}$ si no hubiera metáfora? Entonces nos enfrentaríamos con el peligro de la literalidad, que es el del sinsentido. La suspensión de la moral, junto con la del sentido común, nos deja solos frente al riesgo del "no entendido".

Precariedad, fugacidad, brevedad son solidarias del despropósito, mientras no se pierda de vista que para que el despropósito perdure hay una tensión que no debe resolverse. Dice Tigges: "If nonsense is a game [...] it should be kept in mind that what is essential about this game has been stated very aptly by Huizinga in his Homo Ludens: in games and play ("spel"), it is not the result that counts (in the case of nonsense: to obtain "meaning"), but the process (the maintaining of tension in nonsense)"7 (88).

Esa tensión en sí misma define muchas veces la aventura del relato como despropósito. En "La boda", estrictamente, 'no pasa nada'. Salvo que se crea que la mera anécdota de un marido que engaña a su mujer y deja embarazada a otra sea suficiente para elaborar la trama y cargarse encima todo el peso del relato. Podría serlo, cómo no, pero no es este el caso. Eso que acontece, el engaño como suceso conflictivo, no condensa, de ningún modo, ni el interés ni la fuerza del relato; apenas si los propicia. Interés y fuerza residen en otro lugar, en la fantasía hueca de la narradora protagonista: "Comprendí la verdad: Armando me había traicionado. No

"Si el nonsense es un juego [...] debe tenerse en mente que lo que es esencial en este juego ha sido establecido muy acertadamente por Huizinga en su Homo Ludens: en los juegos y en el jugar, no es el resultado lo que cuenta (en el caso del nonsense: "obtener sentido"), sino el proceso (mantener la tensión en el sinsentido)" (traducción propia; 88). 
pude soportarlo. Pensé primero matar o hacer abortar a golpes a mi rival, después acuchillar o quemar a Armando echándole una lata de nafta encendida; después suicidarme; pero no hice nada, no dije nada" (51).

Esas últimas palabras son definitivas para entender que en este cuento no importan las acciones de los personajes, los sucesos, sino el peso específico de las palabras con las que la narración inaugura un malentendido. El momento más intenso del relato es aquel en que los enunciados "hacer abortar a golpes", "acuchillar o quemar"; abren un hueco, una inquietud a la que es imposible no atender, más allá de que se nos confirme que tales hechos no fueron llevados finalmente a cabo. Si el acento recae en ese 'hueco de la inacción', el final del relato termina -valga la redundancia- de subrayar la tensa calma en que nos deja:

Una mujer enamorada no puede sobrevivir a un engaño. Varias personas me aconsejaron que abandonara a mi marido, pero yo no puedo hacerlo. Por ahora me quedaré con él, porque uno se enamora, después de todo, una sola vez en la vida, pero, si vuelve a ver a esa desvergonzada, lo mataré o me suicidaré. (51)

¿Solo basta con que el marido vuelva a ver a la chica para que ella se anime a cometer el asesinato o el suicidio? Si no lo hizo la primera vez, cuando su marido dejó embarazada a una muchacha, ¿por qué pensar que lo hará la segunda? Parece más bien que la mujer dice lo que no puede hacer, que descarga su ira a través de palabras terribles, mientras difiere, tal vez eternamente, el paso a la acción: "pero no hice nada", "por ahora me quedaré con él", "pero, si vuelve a ver a esa desvergonzada...". Queda claro, queda entendido que la mujer 'no hace nada'. El que hizo algo fue el hombre, pero esa acción, por el modo en que se nos plantea la narración, nos importa bastante poco. Lo que nos atrapa, nos imanta y se apodera de toda nuestra atención es el malentendido al que somos, sin quererlo, arrastrados por las palabras de la mujer. Las leemos prácticamente con la misma intensidad que si estuvieran narradas en pasado. No hay, para la lógica que propone el cuento, grandes diferencias entre "lo acuchillé" y "lo acuchillaré", puesto que la fuerza del sentido habita menos en la "verdad" de los hechos que en la imaginación capaz de dar consecución al relato. La potencia de encantamiento que aviva la expectativa generada motoriza 'la narración como malentendido'.

Ese hueco que el relato abre es el de la dimensión de la expectativa, finalmente frustrada, puesto que nunca asistimos a la ejecución 
cruenta del marido o de su amante, y, sin embargo, en algún sentido sobreentendemos o malentendemos esa venganza. Es que la apuesta de la ficción recae con fuerza en aquello que 'espera' el lector. ¿Cómo es posible, si no, que quedemos prendados de una historia de venganza que nunca se nos cuenta? Como lectores, la presentimos, la intuimos, la 'vivimos', aunque sea como un malentendido o un sobreentendido que no corresponde: el relato de la venganza nunca pasa por "el entendido".

Si, como decíamos, el final acentúa el hueco del malentendido, el comienzo del relato forma con él un tándem de efecto. No por casualidad el refrán con el que empieza el relato, "Casamiento y mortaja, del cielo bajan" (49), junta matrimonio y muerte en los designios de un destino insondable. Se espera que el matrimonio postulado desde el comienzo traiga, mediante el decurso de la peripecia, una muerte como desenlace. Leemos en esa clave, motivada por el dicho popular, como si este imantara a aquel otro que sentencia: "hechos, no palabras". Como lectores habituados a la proyección ulterior de las palabras en un cuento, no creemos en la mera casualidad de la reunión entre "casamiento y mortaja": una expectativa del orden de la creencia se impone y se dispone a esperar la ocurrencia de la muerte en el relato. La confianza crece a medida que leemos el desprecio de la mujer por su marido ("Armando, arrodillado a mis pies, para colmo de mi desdicha..."; "Nos casamos sin que yo lo deseara..."; "No me agradaba Armando..."; "Armando me desagradaba siempre. Sus regalos no lo volvieron más simpático a mis ojos. Se me antojaba que era un bosque [...] o que era un mono..." [4951]). Algo -toda la construcción narrativa-nos dice que esto no puede terminar bien. La aparición de un arma en los últimos párrafos parece anunciar el final inminente: "Dormía con un cuchillo bajo el colchón, por si entraban ladrones de noche. Este detalle, lejos de tranquilizarme, me inquietaba" (destacado propio; 51).

Cuando, luego de un demorado énfasis en el desdén y el rechazo de Filomena por Armando ${ }^{8}$, se dirime en dos breves oraciones el asunto del engaño y el embarazo extramatrimonial, irrumpen sorpresivamente, como en un nuevo malentendido, las expresiones "una mujer

Todo el relato de la boda propiamente dicha, incluido el contrapunto entre la fascinación por los regalos y el fastidio por el marido, apunta en esa dirección: "la fiesta, que después de todo, iba a ser lo más agradable de la boda..."; "mi nerviosidad al contestar al cura si quería a Armando por esposo..."; "Yo me sentía bastante alegre por la fiesta, si no pensaba que era la celebración de mi casamiento” (50-51). 
enamorada" y "uno se enamora”. ¿Qué hacen, nos preguntamos, en este contexto? Volvemos la vista atrás para comprobar que leímos bien: dice "enamorada” donde esperábamos encontrar “enfurecida”, "agraviada”, "humillada", o algo por el estilo. ¿Es que confunde amor con ira? ¿Es que fue seducida por un caso típico del "muéstrame a quién desear"? ¿O es que finge amor para excusarse por su inacción, por no abandonar al marido? Menos que por razones psicológicas, la irrupción descolocada del "enamorada" importa no solo porque es signo del modo en que el relato hace fracasar nuestras expectativas de lectura, sino también porque termina de reforzar la condición impávida del personaje de Filomena. Así como no reaccionó antes frente al desgano y el desagrado ("Nos casamos sin que yo lo deseara ni tratara de evitarlo" [Destacado propio; 49]), tampoco se mueve ahora ni por amor, ni por desamor, ni por fastidio, ni por venganza: nunca hace nada. Las cosas le sobrevienen: “del cielo bajan". En la inercia del personaje, el lector se ve compelido a moverse en su lugar.

Esa suerte de cambio de roles, esa inversión -que, en el orden de la representación, se ha señalado tantas veces en los cuentos de Silvina Ocampo (los niños que dominan a los adultos, las señoras esclavas de sus criadas)-, refuerza en el orden de la lectura una lógica de la invención que pivotea sobre lo que el lector, antes que el personaje, espera, desea, quiere. La potencia de la inversión en la invención también es constitutiva del relato del nonsense como ficción del malentendido.

En rigor, nada sucede: nadie es golpeado, ni asesinado, ni quemado. $\mathrm{Y}$, sin embargo, el sentido que se desprende de esas expresiones y queda flotando como malentendido, vale, por fuerza, lo mismo que si tales hechos hubiesen ocurrido 'en realidad'. Se olvida que en los cuentos de Silvina Ocampo las cosas siempre ocurren "en realidad", como puntualizó Sylvia Molloy, recordando la lección de Carroll (23). El sentido malentendido gana la narración: es la fuerza que todo lo mueve.

Todo el relato nos pone sobre la huella de un acontecimiento que no se produce. Lo que nos atrapa es el sentido flotante -y el poder terriblede las expresiones "quemar vivo", o "acuchillar", o "hacer abortar a golpes", o "echándole una lata de nafta encendida". Ese sentido circula en el relato como malentendido, con una potencia centrífuga que estalla hacia fuera. La frustración final -nada sucede, al fin- exaspera el fracaso como efecto de lectura y con él sobreviene la idea de que 'la ficción ocurrió como malentendido'. 
¿Puede decirse que la ficción está entonces en potencia, solo sugerida? ¿O habrá que pensar que el lugar de la ficción es precisamente el de la mínima distancia que, por la gracia del malentendido, se abre entre la expresión y el acto?

\section{Conclusiones}

Lejos de las formas clásicas del cuento, los relatos de Las invitadas definen su singularidad a partir de una serie de características de interés central para el nonsense: la excentricidad de los personajes, el tono general de impasibilidad y desapego, la atmósfera de indiferente zoncera, el anticlímax, la precariedad de la trama, el despropósito del argumento y la forma intencionadamente inconclusa.

Como las cosas que cuentan los niños, estas narraciones relatan una nada como si fuera una aventura. Tras la pista de situaciones que son, en rigor, antisituaciones, antiproblemas, los relatos se mueven, como los limericks, con velocidad improvisada e inconclusa, hacia ninguna parte. Lo que se cuenta es el hacer nada, la no anécdota de personajes que son una mera extravagancia, una superficie plana, sin profundidad. Intrascendentes, insignificantes, 'sinsentido', los protagonistas de estos cuentos son una nada que proyecta una historia, o un fantasma de historia, que es la de su propia disolución. Regidos por el principio nonsensical de lo pointless -sin meta, sin propósito-, no trascienden más allá de la mínima anécdota que define su destino. Narrativas de lo insignificante, la tontería y la fugacidad, ponen a prueba la potencia del fracaso, de la frustración de la coherencia, del fallido o el malentendido.

Retratos del momento en que una vida se torsiona en un devenir excéntrico se ubican a mitad de camino entre la 'precariedad' de un relato que termina en cuanto concluye la presentación del rasgo idiota del personaje y el 'despropósito' de la ficción como registro de una idiotez. La rareza, ambigüedad y suspensión del sentido característicos de la escritura de Ocampo se impregnan en estos relatos de humor y disparate, para configurar una búsqueda narrativa que hace del juego con las formas del nonsense su apuesta singular. 


\section{Referencias bibliográficas}

Aira, César. Edward Lear. Rosario, Beatriz Viterbo, 2004.

Biancotto, Natalia: "Los cuentos limerick de Silvina Ocampo". Castilla. Estudios de Literatura, Vol. 7, Junio de 2016, pp. 492-516.

Chesterton, Gilbert Keith. “Humorismo”. Ensayos. México, Porrúa, 1997, pp. 132-137.

Dámaso Martínez, Carlos. “Romper el silencio”. Clarín. Suplemento Cultura y Nación. 1987, s/p.

Deleuze, Gilles. Lógica del sentido. Trad. Miguel Morey. Buenos Aires, Paidós, 2008 [1969].

Klingenberg, Patricia Nisbet. Fantasies of the Feminine. The Short Stories of Silvina Ocampo. Londres, Associated University Presses, 1999.

Mancini, Adriana. Silvina Ocampo. Escalas de pasión. Buenos Aires, Grupo Editorial Norma, 2003.

Molloy, Sylvia. “Silvina Ocampo, la exageración como lenguaje”. Sur, no. 320, octubre 1969, pp. 15-24.

Panesi, Jorge. "El tiempo de los espejos: Silvina Ocampo". "Dossier Silvina Ocampo” Orbis Tertius, no. 10, 2004, pp. 93-100.

Pizarnik, Alejandra. Obras Completas: Poesía completa y prosa selecta. Ed. Cristina Piña. Buenos Aires, Corregidor, 1994.

Sánchez, Matilde. Las reglas del secreto. Buenos Aires, Fondo de Cultura Económica, 1991.

Stewart, Susan A. Nonsense: Aspects of Intertextuality in Folklore and Literature. Baltimore, The Johns Hopkins University Press, 1989 [1978].

Tigges, Wim. An Anatomy of Literary Nonsense. Amsterdam, Rodolpi B. V., 1988.

Tomassini, Graciela. El espejo de Cornelia. La obra cuentística de Silvina Ocampo. Buenos Aires, Plus Ultra, 1995.

Ulla, Noemí. “Silvina Ocampo”. Historia de la literatura argentina. Buenos Aires, Centro Editor de América Latina, 1981. 